\title{
A Brief Concerning The MEADOW LAKE PROVINCIAL PARK Provisional Master Plan*
}

(The following are excerpts from the Brief and its Supplement. It consists of he points given in the summary, in most ases with some elaboration from the ody of the Brief or Supplement. It is ess than one-third the length of both ombined.)

In summary, our Society makes these oints:

1. Holding public hearings on evelopment proposals is good for oliciting ideas and comments, and for forming and publicizing.

2. Revise the Parks Act, basing it on a rward-thinking recreation and preseration policy and including stipulations publicize any proposals for changes zoning or leasing of all forms.

From the day of its foundation 25 ears ago, the Saskatchewan Natural History Society has been concerned with he intelligent use of Saskatchewan's ind and resources. The 3,100 members $f$ the provincial and associated local ocieties fully endorse the stated aims of he Parks Act: that "the provincial parks shall be maintained and used as ublic parks and pleasure grounds for he benefit, advantage, education and njoyment of the people of Saskathewan". At the same time we deplore he fact that in 1973, nearly 70 years ince Saskatchewan's establishment as province, we will have no clearly ormulated provincial parks policy ...

The Parks Act (1965) is a limited locument. It is not concerned with ong-range plans, it does not indicate he proportion of provincial land and vater area that should be reserved for rovincial parks, and it speaks only in he broadest terms of park uses (Secion II), making no clear distinction, or instance, between wilderness areas,

Submitted by the Saskatchewan Natural History pociety, February 2, 1973, Saskatoon, Saskatchewan. natural areas, and parks devoted primarily to family recreation ...

The Cabinet can change boundaries, lease parcels of land "deemed advisable in the public interest" (Section 20 , c), or zone any portion of a park "to regulate or confine the various uses of land therein" (Section 20, e). Twice since the Meadow Lake Park was established in 1959 the boundaries have been altered and the total area reduced ...

Since it is becoming increasingly difficult to set aside land for parks, immediate consideration must be given to the establishment of more major parks and reserves and sanctuaries in every ecological zone of the province from the prairie grasslands through the parklands, the transition zone, the coniferous forest and the rugged Precambrian areas of the north Preservation in perpetuity of representative faunal, floral and geological areas must be a chief concern. Smaller (regional) parks concerned primarily with local recreation are already being developed throughout the province and can be expanded more readily than large parks at a later date. .

Finally, a revised Parks Act must take into consideration the rapidly changing public attitudes to parks, and to wilderness areas in particular. Increasingly, people want to escape the crowds of cities; they want to return to nature, to solitude, to fresh streams and rivers, to simple outdoor living. Canoes and sailboats are replacing motor boats; thousands of people are hiking, biking, horse riding, tenting, cross-country skiing, taking pictures and observing wildlife. The time will come, if it has not come already, when great stretches of wilderness and unspoiled rivers like the Waterhen and the Churchill will be considered the greatest asset of our province ...

3. Define the boundaries of in- 
dividual parks by legislation, not by order-in-council.

4. Establish a Parks and Preservation Authority for all provincial parks, wilderness and conservation areas.

To gain broad support for the provincial parks program and to ensure careful consideration of parks policy, a permanent Parks and Conservation Authority should be established with representation drawn from various segments of the provincial community outside the government services, with powers under legislation, and operating in a manner analogous to Wascana Centre Authority . .

5. Because Saskatchewan is behind many other provinces, states and likesize countries in the preservation of the fast disappearing natural scene, stress careful planning and managing of the areas we do have.

The state of New York, one of the most densely populated regions of North America, has $18.8 \%$ of its area in parks and preserves, compared with the
$0.71 \%$ we have allotted in Saska chewan ... The (British Columbia Ecological Reserves Act of 197 provides for the establishing of 10 ecological areas (similar to wilderne areas) by the end of 1975. 27 ha already been established by the end 1971. Within the past few years, Britis Columbia has also cooperated with th Federal government to create two ne National Parks; furthermore it now ha reserved 10,120 square miles in provin cial parks, compared with the 1,80 . square miles set aside in Saskatchewa

6. We reject outright the notion o multiple use within the park, and th blanket classification, "Resort", for sc large a park.

First, we believe that multiple use i: inconsistent with the stated aims of Th Parks Act (cited earlier). The Societ) has sought legal advice and has receivec this response: "In my opinion, the Lieutenant Governor-in-Council is nowhere authorized by this legislation

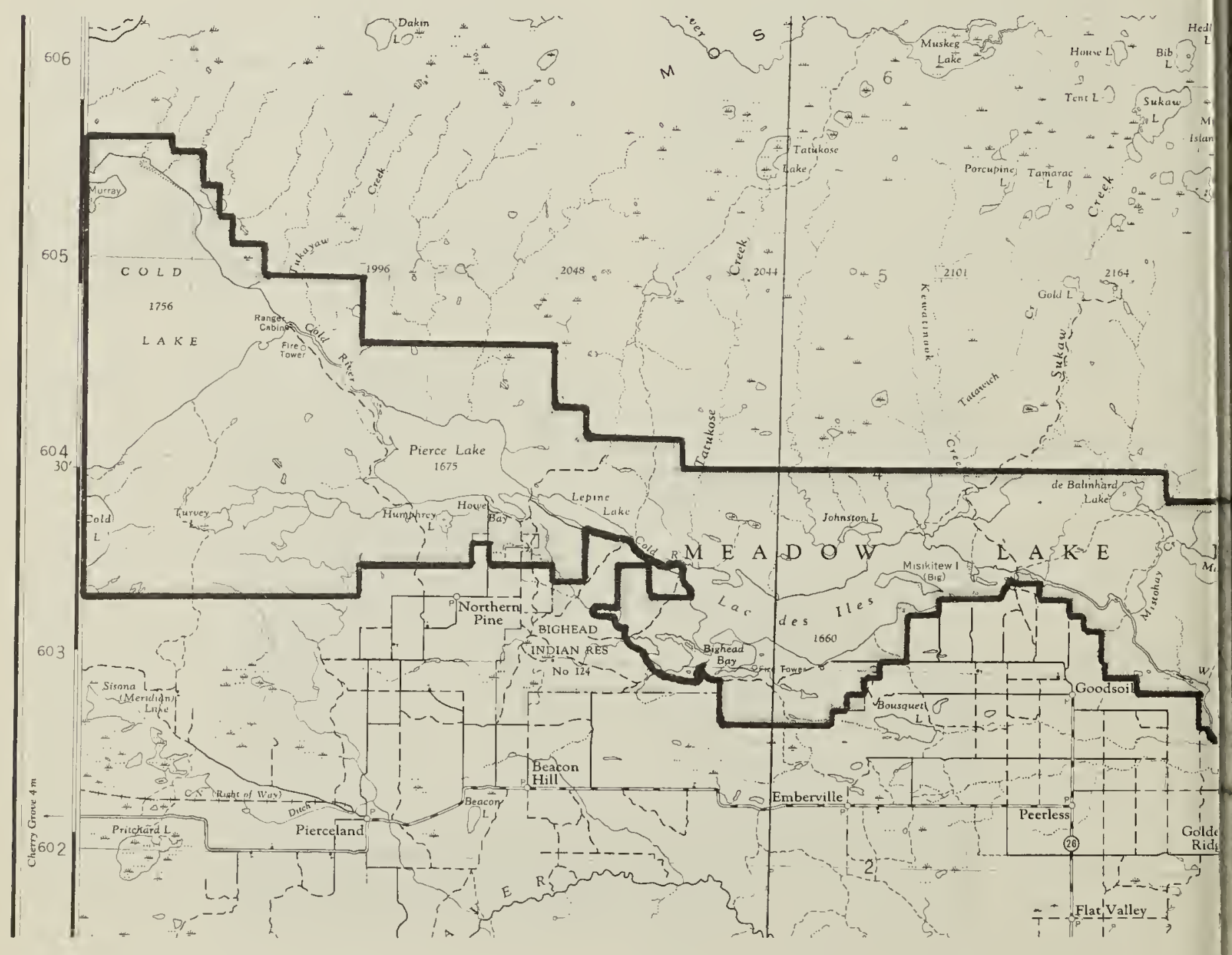

Meadow Lake Provincial Park, Saskatchewan. 
permit or prescribe any use, 'multiple' $r$ otherwise, that is not in keeping with re plain meaning to be ascribed to the mitations implied when the same is ead altogether: i.e. 'Provincial parks hall be maintained and used as public arks and pleasure grounds for the enefit, advantage, education and enyment of the people of Saskathewan'.",

Second, we feel that the peculiar hape of the park (60 miles long, yet veraging only seven miles wide) would lake the results of logging particularly bvious to visitors and destroy the atural beauty of the park ...

Third, in keeping with the convicons expressed earlier about the value $f$ unspoiled areas and the likelihood of creased park usage, and recognizing he fact that complete restoration of orests in this relatively dry area equires between 80 and 120 years, we annot see the wisdom in commercial xploitation of any portion of the park whether it be for lumbering, grazing, gravel removal or the extraction of minerals . .

The Society ... urges that all areas designated for "integrated use" be converted to recreation, natural and primitive zones (Supplement).

7. We support the zoning principle, but propose four modifications in its application to Meadow Lake Provincial Park.

-three extensions of the primitive area, as we have defined,

-an increase to 15 percent the water area with motor boat restrictions, as described ...

Two further categories:

-Protected Zone or Area. Such places in parks as archeological and colonial bird nesting sites and other similarly sensitive areas require special protection to ensure their continuity and preservation. The Park's heron and Western Grebe colonies should be in protected zones ... (Supplement).

-Interim Zoning. In places ... there

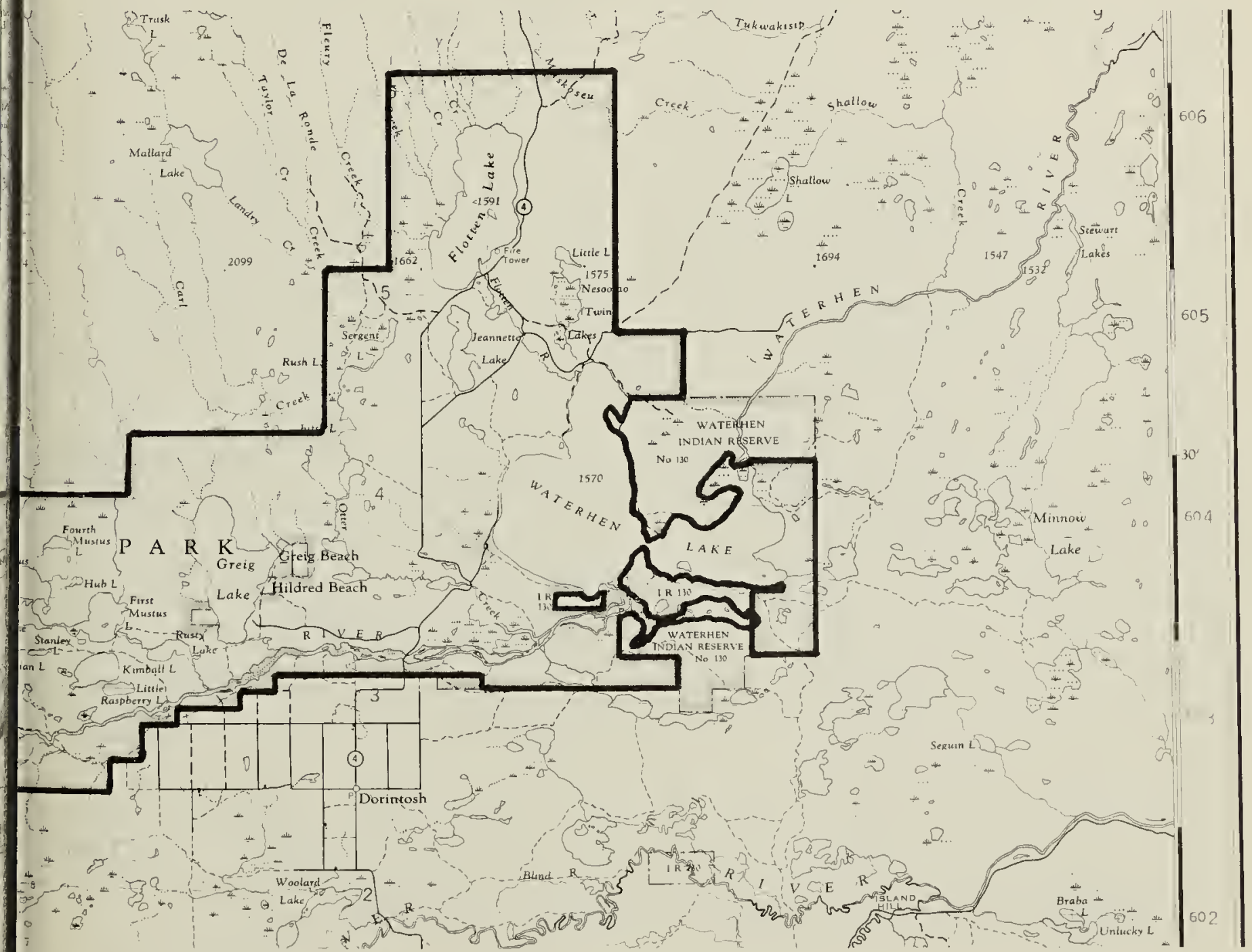


has been an attempt to apply overall principles while at the same time maintaining a status quo; and the two turn out to be fundamentally incompatible. Evidently there is need for a special zoning with an interim or transitional function ... The purpose of such zoning would be to serve notice on all that the previous use is to change, but may continue for a predetermined period - until expiry of a lease, or for a given number of years or up to some other logical termination ... (Supplement)

The campsite area at the east end of Kimball would become a part of the Interim Zones . . . The rapid expansion of campsites at Kimball this past summer was over-hasty, particularly in view of the fact that public hearings were pending. (Supplement)

The Plan suggests that the WaterhenBeaver-Churchill chain affords an opportunity for an extended canoe route. The Province should capitalize on this potential ... A first rate, wilderness canoe trip will yield one of the cheapest and best promotions the Park could receive. Though outside the Park, the lower reaches of the Waterhen and Beaver Rivers will also have to be preserved as wilderness if the potential suggested in the Plan is to be realized

. It is therefore recommended that all of Cold River and Waterhen River (not the connecting lakes) within the Park be classified Natural waters and that 1000 feet of land on both banks be continuously zones as Primitive ... (Supplement)

8. Relocate a portion of the proposed east-west arterial road so as to keep noise and through traffic away from a major woodland lake. ... we believe that a $60 \mathrm{mph}$ arterial highway traversing the park is completely inconsistent with the stated aims of the Park Plan: "that park roads will, to the extent possible, facilitate an enjoyable experience while driving," and "advantage will be taken of the interpretive and scenic values." . . .

The projected use by 430,000 people in 1980 would result in a population density in the park equivalent to that being experienced at Yellowstone
National Park, where 2,000,000 visito now crowd into an area six times large as Meadow Lake Provincial Par Yellowstone's problems are well know

9. As off-road use of motorbikes is ir compatible with enjoyment of the Par by the majority, provide a cross-countr area outside the Park if one is needed

10. Ban snowmobiles from the Park Conservation News . . . reports that "th Bureau of Sports Fisheries and Wildlif has closed experimental trails fo snowmobiles and other off-roa vehicles in three National Wildlif Refuges. Observations of activities the trail sites ... indicated tha snowmobiles do disturb wildlife an harm wildlife habitat." .. .

11. We believe, (a) more rental ac commodation than the Plan sugges will be needed, (b) domestic servic provisions, especially for youn families, may be inadequate, and (c) as principle, accommodation, services etc., should be built by the par authority and operated under con cessions by local people.

We commend your proposal to lim the expansion of cottage subdivisions We believe that people who want $t$ build cottages should be encouraged $t$ buy lots at nearby resorts outside th park. Parks are primarily intended fo all the people of the province, not just few cottage owners fortunate enough $t$ be able to take advantage of the splen did facilities provided by a provinci? park.

12. Ensure that provisions for out door education are adequate.

We are particularly pleased with th decision to reserve an area for an out door education facility at Rusty Lake As soon as the Park Nature Centre i completed, priority should be given to the erection of the outdoor education centre, accommodating not less than 5 students and teachers at a time ...

13. Make preserving flora and faun: - to ensure there is a park wortl visiting a century from now - a corner stone of park policy.

Suffice to say, no time should be los in making inventories of species anc 
special habitats. Every effort must be hent towards protecting rare birds and plants in the park; the heronry in the Mustus Lake area is a good case in point Mature and over-mature hardwood and softwood stands form the natural habitat for some of the less common hirds and plants and, at times, for some nammals ..

Knowledge of the resource is essential before plans are finalized - if for no other reason than to avoid the sort of hideous mistake made in Pike Lake Provincial Park. There a parking lot and playground were built on a bog, one of the few places in central Saskatchewan where wild orchids grew . . .

14. Seek the views of the hiking fraternity on the merits of a hiking trail the length of the Park.

Your recognition of the need for hiking trails is valid. While a total of 30.5 miles is recommended for the present, with several more proposed for a later date, we believe that many hikers would welcome a hiking trail extending from the Alberta border to the northeast end of the park. It could well become one of the most popular attractions of the park ...

15. Do not use beaches for warehousing private or rental boats.

We applaud, in particular, the following recommendations contained in the Master Plan: ... .

-the proposals to purchase land along the south boundary of the park in order to preserve park landscape and to discontinue cultivation of crops within the park.

- the establishment of a Park Nature Centre and six self-guided nature trails...

- plans for a more rigid and consistent building code with a unifying architectural theme.

- the consideration being given to employing Indians . .

If the Park is less than visitors and tourists expect of a park today, money spent on promotion will be wasted. A good park, well planned, managed and preserved is its own advertisement. The Meadow Lake Park area contains some of the most beautiful lakes and scenery in Canada. This Master Plan is well along in seeing that it can be maintained. Take the Plan the last mile to ensure that all visitors, now and in the future, will carry away pleasant recollections.

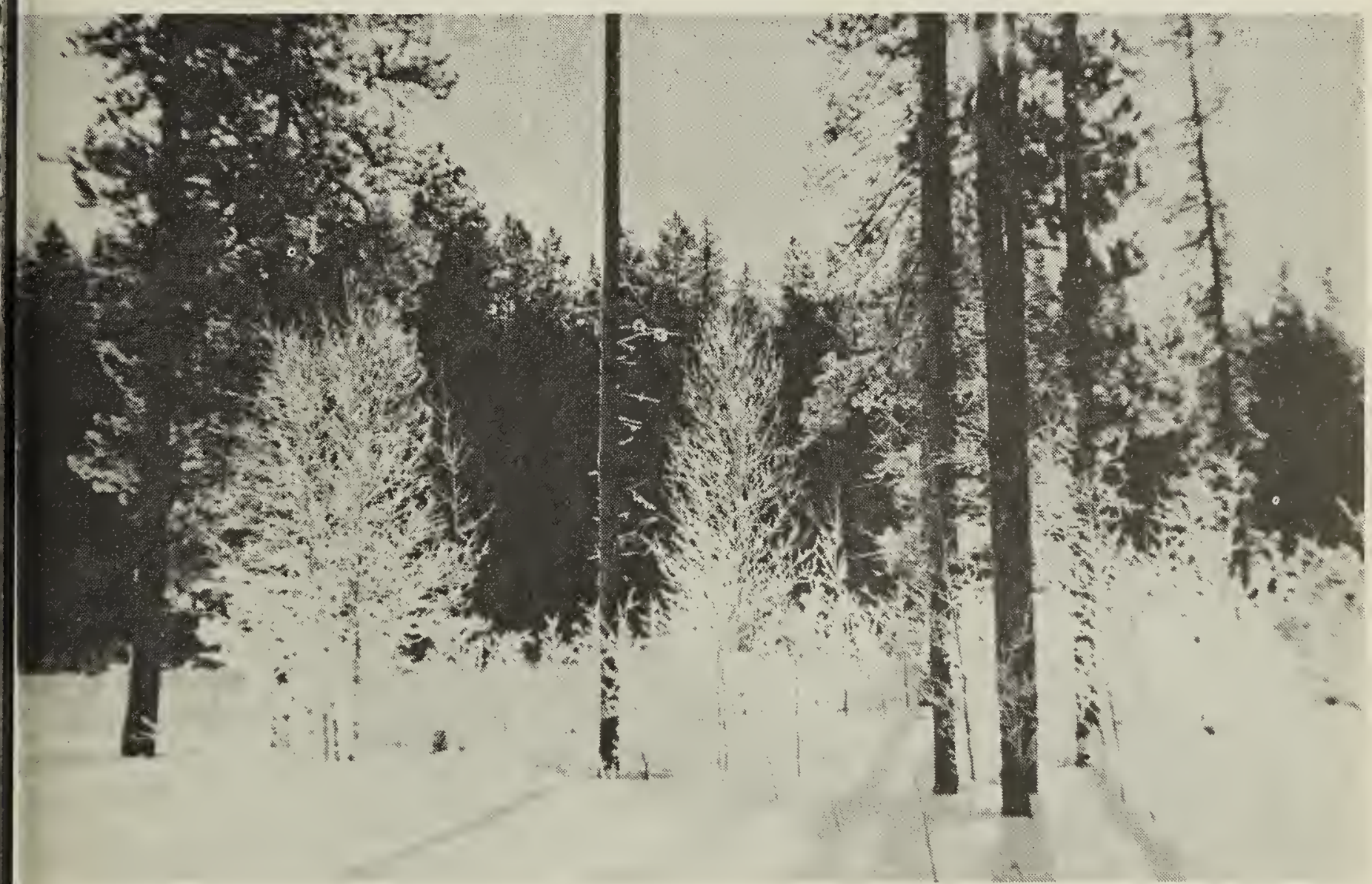

Trees backlighted in snow. 